"The ideal Russian speaker is no Russian": Language commodification and its limits in medical tourism to Switzerland

Sebastian Muth

Senior researcher

Institute of Multilingualism

University of Fribourg/HEP Fribourg

Rue de Morat 24

CH 1700 Fribourg

SWITZERLAND

sebastian.muth@unifr.ch

Tel. +4126 3056176 


\section{"The ideal Russian speaker is no Russian": Language commodification and its limits in medical tourism to Switzerland}

\section{Introduction: Language commodification, neoliberalism and the global patient}

Der Gesundheitsmark.t ist ein sehr stark wachsender, von wirtschaftlichen Turbulenzen relativ unberührter Markt (auch in schlechten Wirtschaftszeiten will niemand sterben, wenn er die Mittel hat, sich heilen zu lassen) mit grösster Bedeutung für die Schweizer Wirtschaft.

The bealthcare market is a fast-growing and relatively turbulence-free market (also in economically challenging times nobody wants to die when he has the means to get healthy again) with great importance for the Swiss economy (Swiss Health Services 2008: 26)

Indeed, this excerpt from the founding meeting of Switzerland's marketing body to support the county's entry into the market of medical tourism marks the reinvention of an image of the country to profit from a recent phenomenon linking health and the neoliberal economy, medical tourism and the global movement of patients across borders. Similarly, at least from a Western European perspective it also highlights a decisive shift and the departure from perceptions of healthcare as a largely public provision towards an expression of the global new economy, where patients become consumers, hospitals competitors, and access to quality healthcare is determined by the patient's ability to pay (Connell 2013). Although relatively recent in its current form, neither medical tourism nor Switzerland's image as a destination for affluent patients wishing to seek adequate healthcare are new to a country whose service industry has catered to the global rich since at least the past two centuries (Tissot 2010). However, from the early 1990s and the onset of globalization and the new economy, international travel to access (better) health infrastructure saw an unprecedented rise with approximately 7 million patients travelling across borders for healthcare annually, becoming an expression of privilege, individualism and entitlement, yet for some also a necessity (Chuang et al. 2014; Connell 2013, 2015; Smith and Puczkó 2014). When, following the world's financial and economic crisis in 2007/2008, Switzerland entered this global market, the country's image as a premium tourism destination, a place of luxury and leisure as well as that of a developed, technologically advanced nation became recurring tropes in the promotion of medical services. However, one aspect that is frequently highlighted in promotional discourses (Del Percio 2016) proved to be the most challenging, the promise of Switzerland as a multilingual country where patients - in this case private, self-paying medical tourists - can expect to undergo treatment in the language of their choice.

With regard to language this opens up a perspective that is intrinsically tied in with the logics of both market expansion and the creation of niche-markets, in turn being closely connected to the valorization or commodification of languages and speakers within the globalized new economy (Cameron 2000; Heller 2003, 2010; Heller and Duchêne 2012; Piller and Takahashi 2013; Tan and Rubdy 2008) and - as a consequence - neoliberalism as a covert form of language policy (Piller and Cho 2013). Within this global new economy that explic- 

accommodation in a language of choice, but can turn into a decisive marketing argument to attract patients who share specific linguistic and cultural backgrounds (Muth 2015).

These are also the focal points of this paper and the ethnographic research it represents, on the one hand aiming to examine the management of multilingualism in the Swiss healthcare industry and the negotiation of the oftentimes fluctuating and unstable value of linguistic resources in the care for medical tourists; on the other hand highlighting how international healthcare and medical tourism emerge as sites emblematic of the global new economy and the exploitation of those linguistic resources. Insights will be drawn from two research sites that are currently engaged in the care of international patients, a private medical clinic and spa I call Mountain Medical Resort as well as a public general hospital I call Lakeside Hospital. While both institutions offer to provide assistance and translation in a number of languages, this research primarily focuses on Russian as the language spoken by the largest share of medical tourists at both sites and in Switzerland as a whole. In particular, it is my aim to highlight how Russian as a linguistic resource is managed at Mountain Medical Resort (hereafter, MMR) and Lakeside Hospital (hereafter, LH) to attend to visiting international patients. This will illustrate, which specific linguistic proficiencies are deemed valuable and how changes in market conditions and patient numbers have an impact on the commodity value of languages and that of Russian in particular. Here, it is the aim of this research to examine how, in which instances and under which conditions languages gain and may again lose a marketable value and how institutional policies react to that. Based on the two research sites that are exemplary for the current rise in numbers of medical tourists seeking treatment in Switzerland as much as they represent the transformation towards health as a consumable product, this also implies to examine how the neoliberal transformation of healthcare is connected to the re-imagination of language as a commodified skill under current political-economic conditions (Park 2016: 453). Exemplified by medical tourism as a key site of the global new economy and Russian as a potentially commodifiable linguistic resource, this will also leave us with broader implications on the changing regimes of value of languages and on the role of language in the neoliberal economy.

In the following, this paper will first exemplify how languages as resources are inextricably tied in the global new economy in times and conditions that arguably allow for the commodification of virtually everything (Appadurai 1986). In that respect, the global new economy and accelerated capitalism and globalization also constitutes a major element in the advent of what in the past has been called global medical mobility, medical travel, -tourism, the movement of patients across borders, or medical outsourcing (Connell 2013; Crozier and Baylis 2010; Jones and Keith 2006). This incorporates a closer perspective on the notion of language commodification, its language ideological underpinnings and relation to language policy in healthcare and beyond, its implications for the management of linguistic resources in the service economy as well as to reverse phenomena such as potential limitations in the valorization of languages and speakers. This is followed by a dis- 

borders, highlighting the development of this by now global phenomenon "[...] imbued with capitalism, entitlement, individualism and self-fulfillment" (Connell 2013: 2). Here, the perspective will be primarily on the emergence of Switzerland as a premium destination in contemporary medical tourism, yet will also include other competing markets that aim to attract patients internationally. As a next step I will introduce the two research sites I draw from, the private health resort MMR as well as the public hospital LH. Both witnessed a substantial growth in self-paying patients with varying linguistic and cultural backgrounds within the past 10 years and I will show how this increasing internationalization has implications for the commodification of languages and speakers, for institutional language policies as well as for the management of multilingual workers who are directly involved in the organization and planning of medical travel and who provide assistance to medical tourists throughout their stay. Apart from commodifying and policing languages and speakers this also entails processes of language devaluation that are results of volatile and shifting market conditions, diverging attitudes towards the desired cultural and linguistic backgrounds of those who commodify their linguistic resources, as well as constraints in the management of both foreign-language speaking patients and multilingual medical workers. The concluding chapter will then emphasize the role of fluctuating commodity values and the interplay between language as resource and efforts to manage, control and - at times - devalue those linguistic resources.

My data for this research is part of a multi-sited ethnography (Marcus 1995) on the commodification of language in medical tourism to Switzerland and come from a number of sources and are comprised of 1) ethnographic fieldwork, audio-recorded interviews and participant observations at the two main research sites, MMR and LH's International Office, 2) interviews with stakeholders in the Swiss healthcare industry that includes healthcare brokers, a representative of Swiss Health Services and freelance medical interpreters, as well as 3) the examination of promotional materials both online and in the form of brochures and magazines. Site visits to MMR took place between March 2014 and January 2015 and then again from September 2015 until June 2016 and were both observational and comprised of interviews with stakeholders in the management of the clinic, in public relations and marketing as well as language teaching. By combining perspectives from the management of the medical clinic responsible for long-term strategic planning, from public relations and marketing responsible for the promotion of MMR on international healthcare markets, as well as from human resources engaged in language training for employees, it is the aim to better understand the processes of language valuation and devaluation from a multitude of perspectives. At LH, I also rely on interviews and observational data from fieldwork conducted from April and May 2014 as well as a follow-up visit in May 2015. Contrary to MMR, ethnographic fieldwork was only conducted in LH's international office, a department of the hospital established to plan and coordinate visits of medical tourists and provide adequate language services according to patients' requests. To learn about marketing strategies and the positioning of Swit- 

and medical tourism fair in Moscow in September 2015.

\section{Language, neoliberalism and changing regimes of value in space and time}

When I started to explore language commodification in the Swiss healthcare industry in early 2014, one of the first research sites I visited was a healthcare broker based in an affluent neighborhood in Zürich in close proximity to a number of public and private healthcare facilities. Apart from mediating between hospital and patient, work scopes in this particular enterprise also included to accompany patients and their relatives throughout medical treatment in Switzerland. At that time, promotional discourses of prominent Swiss hospitals and health resorts heavily relied on promises to provide state-of-the-art medical treatment pared with the assurance that patients will be accommodated in the language of their choice, a promise that became reality for the healthcare broker, catering almost exclusively to patients from countries of the former Soviet Union speaking Russian as a first or second language and having limited command in English and none in German. In particular, my question to name an ideal medical worker in charge of Russian-speaking guest elicited an initially rather unexpected response, as:

“[...] the ideal worker for us speaks Russian, but should not be Russian as this is an issue of trust. Russian skills appeal to our patients and attract them to us, but nowadays for Russian patients not every speaker is suitable. Speaking Russian with a Swiss accent would be best but almost impossible to find." (personal communication, 20.02.2014) $)^{1}$

While this gives a first insight into the preferences of Russian-speaking patients as it highlights the wish to be detached from all that even remotely relates to healthcare back home, it raises the question about who actually is legitimate and authentic enough to represent an image of a multilingual Switzerland that presents itself as an exclusive healthcare destination. Furthermore, it also manifests the notion of language as a resource and language commodification as inherent to the global new economy, that at the same time is affected by fluctuating markets as well as shifting values and perceptions on languages and speakers. For the healthcare broker in Zürich, linguistic resources in the form of speakers proficient in both German as the language of the hospital, and Russian as the language of the patient did not constitute an added value to their service per se and would not allow to weight in language as part of promotional discourses in Russian-speaking healthcare markets. Instead, while certain linguistic resources indeed promise market expansion and capital gain for the healthcare broker, only for particular speakers with clearly-defined cultural backgrounds - in this case Swiss who master Russian - this translates as an additional symbolic capital.

From a broader perspective, we may view the commodification of language as a site that transforms and mobilizes symbolic capital to become interchangeable with material capital (Bourdieu 1977; Heller 2003; Heller

${ }^{1}$ This and all following interviews were conducted in German and translated into English by the author. Because of space-constraints, only translations into English are shown. 

are expressions of language ideologies that manifest social hierarchies and as such highlight a shift towards neoliberalism and the entry of semiotic products of nationalism - including language - into processes of commodification (Heller and Duchêne 2016: 141). Furthermore, in instances that demand the availability of particular linguistic resources at particular moments in time, the policing and management of speakers is in direct relation with efforts to commodify available linguistic resources, creating the conditions for any commodification that may provide added value.

This is particularly true in relation to the service industry where a great deal of attention is paid determining "[...] the value of the intangible" (Heller and Duchêne 2016: 141). Addressing these uncertainties inevitably implies some form of language policy and planning, an aspect that also became salient for the healthcare broker in Zürich and, as we will later see, also for the two healthcare facilities MMR and LH. In turn, this also implies that the commodification of language is closely related to the political-economic conditions within communities that may constrain but also alleviate meaning-making and social relations through language (Gal 1989; Heller 2003; Irvine 1989). This commodification of languages, cultures and speakers (Heller 2003, 2010; Urciuoli and LaDousa 2013) primarily describes how language and identity as symbolic capital not only frame meaning, social relations and social identities, but also become resources with an inherent exchange value with language and identity as marketable commodities. This however does not come without tensions and epistemological uncertainties, as a perspective on linguistic resources being detached from the social world as commodifiable objects raises questions about the explanatory power of the conception as much as it prompts concerns over the separation of the language skills from general abilities of workers (Holborow 2015) or the apparent lack of quantifiable capital gains as a result of the utilization of those skills (McGill 2013). For the healthcare broker in Zürich though, language is a work product that can be commodified and choosing the 'right' speaker may even be measurable in patient numbers. Here, the decision whether or not a certain linguistic resource is marketable remains intertwined with both political-economic conditions and prevailing language ideologies as much as it is constantly in a state of renegotiation and change. From this perspective, commodification is neither limited to labor where language itself cannot be commodified and as such remains intertwined with work processes; nor can it be separated from general abilities of workers (Holborow 2015). As we will again later see, especially in the service economy and in healthcare in particular, the commodification of language can be viewed both as a work process and work product with language as a measurable skill (Heller 2010) and one of the most central and decisive work products (Boutet 2001; Duchêne 2009; Heller 2003, 2010).

This implies yet again a broader view, connecting the commodification of language to the notion of language as resource and its role within the neoliberal economy. Here, language commodification may have two basic expressions, as a technical skill (Taylorization) and as a sign of authenticity and distinction (niche markets) for 

communication and customer-based services are now offered on a global scale, resulting in increasing communication across cultural and linguistic boundaries and calling for an explicit management and policing of linguistic resources. This points towards standardization and Taylorist' practices in language production as much as it implies the emergence of niche markets where certain linguistic and cultural preferences add largely symbolic value to products and services. While in the former, language production is centered on standardized communication that requires particular languages, sets of practices and forms (Boutet 2008; Cameron 2001; Heller 2010), finding, among others, its expression in the call center industry, the latter is closely related to notions of authenticity, where "[s]tandardized goods can be made special by being marketed as local, authentic, and in some ways unique products with limited distribution" (Coupland and Garrett 2010; Heller 2010: 350). This uniqueness is not explicitly related to language and can take on other forms such as the promotion of products with designated origins and ways of production to add symbolic value that appeals to certain consumers. In this respect, we may draw from the idea that uniqueness and authenticity also entail questions about language use and cultural preferences of (desired) consumers from different markets and how those can become added values for products or services (Heller 2010).

This also highlights a unique product of the service industry that goes beyond medical care but constitutes a driving force for market expansion and a competitive advantage through multilingualization (Cameron 2001; Duchêne 2011). However, with the desire to create niche markets and to promote certain languages, speakers and their linguistic resources, communication becomes closely related to language management and -planning, as preferences of consumers tend to be highly diverging depending on their countries of origin, languages spoken, or cultural backgrounds, an aspect that is highlighted in the broker's speculations on who produces the most commodifiable Russian for his patients. Furthermore, those preferences are rarely stable and the value of languages and speakers as commodities is intertwined with particular market conditions, economicand political developments that naturally also have an effect on individual spending power, as well as changing preferences by consumers. These changing regimes of value in space and time (Appadurai 1986) also have an impact on how enterprises in the new economy engage in language policy and planning within their institutions. While it is within the logic of the globalized new economy to employ strategies of market expansion that require specialized skills, such as proficiency in lesser-taught languages that add value to a particular service, fluctuating market demands may highlight under which conditions certain linguistic resources become less desirable both for consumers and the economy. Amid fierce competition among providers of medical services, these fluctuating market demands are also characteristic of flows of medical tourists (Chuang et al. 2014; Connell 2013). 


\section{'Niches for riches': Switzerland in global healthcare}

When in 2008, policy analysts, stakeholders in the Swiss healthcare and tourism industries and representatives of the country's Secretariat for Economic Affairs (SECO) and the government agency for trade relations and export promotion, Swiss Global Enterprise gathered at a Swiss think tank ${ }^{2}$ to launch a nation-wide strategy to promote medical travel to the country, tourist numbers stagnated and the image of Swiss healthcare abroad was largely historical, relating to the past glory of mountain resorts and spa towns in picturesque alpine settings. This was also the founding moment of Swiss Health, a marketing institution jointly established by Swiss Global Enterprise and Swiss Tourism, the national organization responsible for the promotion of tourism to the country that currently (2016) represents 22 public and private hospitals and medical resorts internationally (Swiss Health Services 2016). With the absence of comprehensive data on the number of incoming medical tourists, at present representatives of Swiss Health as well as patient managers at both MMR and LH estimate that approximately one to two percent of all visits to Swiss clinics and healthcare facilities account for medical tourists (MMR; LH, personal conversations). The strategies for reestablishing a favorable image of Switzerland in global healthcare markets are similar to the promotional discourses Swiss Tourism has been articulating since its foundation (Duchêne 2009), centered on promises of high-end, professional medical care in a country traditionally associated with good health, a clean environment, excellent infrastructure, a tradition of multilingualism, discreetness and the possibility to enjoy other services such as investment banking, luxury hotels and leisure shopping (Swiss Health Services 2008). The initial theme was summarized as providing "niches for riches" (Swiss Health Services 2008), highlighting the exclusivity and prestige that Switzerland offers. While those niches may potentially appeal to the global rich regardless of their origin, based on market research and already existing experiences by hospitals, patients from 'totalitarian and post-totalitarian regimes’3 such as Russia, Kazakhstan, Saudi Arabia and the United Arab Emirates moved into the focus of medical service providers to fill Swiss hospital beds (Swiss Health Services 2008). This also implies that patient movements are highly socially stratified and as such, Swiss healthcare providers do not compete with most medical tourism markets. While long-established healthcare destinations like Germany, Thailand and Singapore or new competitors from India, Malaysia, South Korea, or Turkey largely attract middle class patients from around the world, other focus on particular patients, medical fields and/or countries of origin (Connell 2015; Dewachi et al. 2014; Smith and Puczkó 2014; Turner 2007; Viladrich and Baron-Faust 2014).

While promotional discourses connect Swiss multilingualism with entitlement, prestige, precision, privacy and the ability to access all of the country's tourism and financial infrastructure (Swiss Health 2008), this discursive construction of healthcare in Switzerland is not primarily grounded in the promise to offer services in a particular language for patients from a particular geographical region or cultural sphere, but instead views the

\footnotetext{
2 the Gottlieb-Duttweiler-Institute (GDI) is a Swiss Think Tank that engages in market-oriented research on trends in consumption, www.gdi.ch ${ }^{3}$ Original in German, "[...] Patienten aus totalitären und post-totalitären Regimes.“
} 

2016; Duchêne 2009). Based on the two research sites emblematic for the internationalization of Swiss healthcare, Mountain Medical Resort (MMR) and Lakeside Hospital (LH), I will point out these uncertainties that effectively limit which linguistic resources can be commodified and for whom. Furthermore, this negotiation of the value of linguistic resources also accentuates institutional efforts to police and manage languages and speakers as much as it illustrates the difficulties and organizational challenges that come along the promise of multilingual service for medical tourists.

\section{Medical tourism to Switzerland in context: the two research sites}

In the following I will briefly introduce the two research sites. With regard to MMR this also incorporates a decidedly historical perspective meant to illustrate how medical tourism to Switzerland is tied in with historical contexts, economic conditions and the repositioning of the country as a healthy destination for the global rich. LH on the other hand was a relative newcomer to the field of medical travel and as such particular attention will be paid to the hospitals' policy of market expansion, putting a special emphasis on the provision of multilingual services for patients.

\section{Mountain Medical Resort}

In 2016, MMR can look back to about 150 years of providing services to patients and tourists alike as a spa and healthcare clinic and as such, its history as one of the most widely known and prestigious Swiss resorts resonates throughout its promotional discourses. Indeed, highlighting the multitude of international guests for whom MMR embodied Switzerland as a premium destination since the mid-19 ${ }^{\text {th }}$ century is one of the central themes in the promotion of the resort in international markets, paired with its pristine alpine setting, thermal waters and convenient transport connections towards the German-speaking urban centers of the country. What started as a stopover point for wealthy English travelers on their way to destinations in the Swiss Alps and beyond soon developed a sizable tourism infrastructure including a golf course and luxury accommodation. By the early $20^{\text {th }}$ century, MMR attracted wealthy and oftentimes famous visitors from around Europe for medical rehabilitation. However, following the First World War, the resort was forced to close amid economic crisis and declining numbers of visitors. Reopened in the late 1950s, MMR retained its exclusive clientele for much of the remaining half of the $20^{\text {th }}$ century, yet changing global tourism flows, the onset of affordable long distance travel as well as the onset of the spa and healthcare industry in its current form once again led to declining numbers of visitors and - as a marketing and public relations expert at MMR pointed out during a tour through the resort - was widely perceived as being out of time (personal conversation, 13.09.2014). In the 1990s and in anticipation of changing healthcare markets, MMR redefined itself as a wellness and healthcare resort, demolishing some of its historic building structures and rebuilding them in a similar architectural design but with a new interior and room layout. Furthermore, the resort added a luxury tow- 

sentative commented - luxury hotels and spas around the world in both comfort and security (personal conversation, 13.09.2014). MMR now includes a medical center, a rehabilitation clinic, a spa, a small shopping arcade featuring luxury brands and multilingual sales personnel, an employee training center and a kindergarten where little guests are taken care of in five languages, among them English and Russian. Its newly established medical center is at the heart of MMR's efforts to profit from global medical tourism and is focused on small surgical procedures and post-operative rehabilitation that for now have proven to be commercially successful by combining MMR's history as a famed health resort with modern, state-of-the-art medical care. As of 2016, in total MMR employs around 700 medical and non-medical workers, approximately half of them are Swiss nationals with the rest being comprised of migrant workers mainly from countries of the European Union. Its visitors and patients are predominantly from Switzerland and Germany, yet a large number (although in conversations it remained unclear what large means) of guests to both the spa and the medical clinic come from the Arabian Peninsula and countries of the former Soviet Union, first and foremost from Russia. Because of its global clientele but also because of its international workforce, MMR puts significant emphasis on language management, highlighting in-house language teaching to employees as a core element of its Corporate Social Responsibility. In the past, MMR ran in-house language courses in Arabic, English, German, Italian and Russian and currently offers English courses to its employees (MMR annual reports 2012-2015).

\section{Lakeside Hospital}

Unlike MMR, LH's main focus is on serving the public of an urban agglomeration in the German-speaking part of Switzerland. It is neither engaged in leisure nor spa tourism and does not look back to a longstanding history of serving medical tourists. Currently LH is one of the largest Swiss hospitals and offers comprehensive medical care in virtually all fields. It has over 7000 employees and - similar to MMR - praises itself for its culturally and linguistically diverse workforce of which roughly one third are no Swiss nationals. Because of its size and the hospital's mission as a healthcare provider for the general public, international guests are not LH's core generators of income, yet given the relatively high cost of medical care in Switzerland, it is very lucrative. To attract and take care of medical tourists and to serve as a first point of reference, LH maintains an International Office responsible for the coordination of patient visits from abroad. Also, the International Office engages in marketing efforts for its medical services and does so in cooperation with Swiss Health. Similar to MMR, LH aims to operate in the niche market of medical care for the world's most affluent medical tourists and largely shares MMR's target markets. If compared to MMR, LH's promotional discourses are centered on the provision of high-end medical care, connecting tourism discourses of Swiss precision and quality with healthcare as both a necessity and lifestyle choice. LH's International Office is able to draw from over 1000 physicians within the hospital and as such is able to offer both complex surgical procedures as well as medical check-ups. In anticipation of future growth, LH currently awaits the opening of a medical clinic in close prox- 
imity to an international airport, hoping to facilitate a further growth in patient numbers from abroad by offering tailor-made services for international patients. Within its International Office, LH employs a multilingual workforce and while patients can browse its website in English and Russian, they are ensured that staff at the International Office has the ability to speak German, English, Italian, French, Russian, Ukrainian, and Chinese. Furthermore, LH's International Office is able to provide translation services in a wide array of languages for patients and accompanying relatives upon request and assists in patients' visa applications and travel arrangements.

\section{The commodity value of languages and speakers within changing markets}

For both MMR and LH the prospect of receiving medical tourists promised economic growth, expansion and profit, prompting them to include the provision of medical services in the language of the patient as part of the authentic product of healthcare in Switzerland and as a sign of distinction signaling Swiss hospitality. At the same time, this internationalization of patients and the commodification of their languages also came at a considerable cost, relating both to the training and sourcing of medical- and hospitality workers, in the management of this multilingual workforce as well as in the unpredictability of market developments.

\section{'Paying attention to language'}

To highlight this, I will first take the perspective of MMR, focusing on the recent establishment of its medical center that became a key component in the resort's efforts to profit from affluent medical tourists. Indeed, as the managing director (JL) of MMR's medical clinic who has been in charge of marketing MMR on Russian speaking markets since the late 2000s emphasized,

“[...] some time ago it was enough to be a hotel with a nice spa, today customers need a 'reason why' to come here and find this in different things, be it golfing, or the spa or healthcare so that we now can focus on particular clients' needs as medical care, health and a balanced lifestyle become more important" (personal conversation, 19.09.2014)

With the notion of health becoming more important and MMR aiming to transform into a healthy retreat for the world's rich, the medical center took on a decisive role within MMR, offering a comprehensive range of both therapeutic and preventive healthcare ranging from inpatient rehabilitation, dietary planning and health check-ups to aesthetic and plastic surgery. Based on patient numbers, guests from Russia, other post-Soviet republics as well as the Middle East took a leading role, also showing on its website that - apart from German and English as 'hypercentral languages' (Kelly-Holmes 2006) - can be accessed in Russian and Arabic. While affluent patients may now organize their stay in MMR just like booking a hotel and may even phone the resort to find English- and Russian-speakers readily available, serving this particular niche market of high-end medical care required additional incentives. At first, the ability to take care of patients in their first language per se 

come here and we will take care of you in your language?

JL: Yes, yes, ehm this is definitively, this is definitively important. especially for the Russian market. and currently I'm still responsible for sales for all those Russian markets and this is extremely important for them. for the travel agency this is a two-edged sword as the client at some point realizes that there is always someone who understands me. today clients have multivisas and can come and go as they please. because they know that there is someone whom I can understand and whom I can call and I can book a room for two weeks. then the intermediary disappears and this is unfortunate for them $[\ldots]$

SE: aha

JL: but on the other hand they want us to have Russian-speaking workers available because they know they arrive here and they don't understand anything and they are completely lost. and we don't want that for our guests. we want that they feel good here and that they can do something around here [...] (personal conversation, 19.09.2014)

Apart from pointing towards the necessity to provide adequate service in the language of the patient as part of the overall marketing strategy of the resort, market expansion and capital gain through multilingualization may also take on more subtle and implicit forms. In fact, circumventing the services of healthcare brokers (who receive a commission for each patient) through the strategic marketing of multilingual services and the assurance that communication with the resort will be possible in Russian translates as capital gain for MMR and an effective economization of multilingualism (Duchêne 2011). Within this context this primarily refers to Russian, as English-proficiency does not necessarily provide MMR with a competitive edge in the industry and is largely taken for granted by guests. The properties of Russian as a commodifiable language for the resort is also highlighted by those engaged in the sourcing of medical- and hospitality workers for MMR and its medical clinic. In a conversation about the recruitment of Russian speakers, the head of human resources development (MT) claims that for Russian guests, services in Russian are indispensable:

MT: and then we have specialists who speak Russian. most of the time they are ethnic Russians. we pay a lot of attention to them

SE: $\mathrm{mhm} \mathrm{mhm}$

MT: and we have two three people who directly work in guest relations and who organize all visits. they can accompany patients as translators during their treatment. in fact, for the Russian patients they act as persons they can trust and who speak their language. they are in charge of everything, it's the patient's wish (personal conversation, 20.11.2014)

In this context, the notion of 'specialists' refers to both medical specialists such as dietary planners and medical care workers as well as patient service or guest relations managers. Here, the latter group of Russianspeakers is of particular importance and hold a key position at the resort, as they become reference points for 

resources. However, during my fieldwork it emerged that the promise to provide multilingual services alone is not deemed sufficient for MMR and in the past years, MMR's medical center has engaged in language planning efforts to determine the most suitable speakers and the most appropriate language proficiencies that may provide an added value to its services. As it turned out, a significant aspect relates to perceived characteristics of target markets and while for certain patient groups like Russian-speakers, any Russian could be commodified per se, MMR's medical clinic soon discovered that for the effective functioning of the medical center, not every speaker may fulfill that role after all. Interestingly, this does not correspond to the ideal of the Russianspeaking Swiss the healthcare broker in Zürich highlighted earlier on, but instead relates to particular cultural backgrounds that would ensure an uncomplicated and tension-free running of the resort. Especially the managing director of MMR's medical clinic who is actively engaged in the acquisition of patients on Russianspeaking markets has a clear understanding of the properties of the resorts' Russian-speaking workforce and guest relations managers in particular:

SE: Who would be the ideal patient manager for you? for a Russian-speaking guest? what kind of cultural and linguistic background should he have?

JL: Ehm. I'm not sure if it can be a Swiss because I definitely believe that for us as Swiss it is at times difficult to accept the conduct of Russian guests as it is. and I don't mean. they are absolutely polite but they have an own way. their own culture. and because of that I think it makes sense that it is a Russian native speaker. but who maybe has lived in Switzerland for a long time and speaks German very well. and who knows the Swiss system. be it healthcare be it our culture how we deal with appointments and punctuality and so on. this is part of it

SE: $\mathrm{mhm} \mathrm{mhm}$

JL: And yes. I have to say that I'm lucky. I have someone who is very very dutiful and can also get that across $[\ldots]$ the whole conduct. that you understand the conduct of your clients. because sometimes they react in a certain way and the Swiss would be upset because he thinks yes I've tried so hard. and the Russians know this. they know that he [the client] doesn't mean it that way (personal conversation, 19.09.2014)

As much as this highlights cultural predispositions and stereotypes, this example clearly shows that for MMR and its medical clinic in particular, a profound familiarity with the cultural background of patients is essential and that as such, not every speaker is equally suited to 'understand' Russian-speaking guests. Here, linguistic resources alone then do not necessarily provide an added value and gaining an understanding of patients' wishes and preferences emerges as an integral part in the promise to provide high-end services while at the same time it ensures that the resort is able to match patients with the most suited service worker both linguistically and culturally. In addition to that and to ease cultural barriers that, in the understanding of JL, inevitably come up, the medical center decided to compile cultural guides, highlighting the do's and don'ts when dealing with Russian- and Arabic-speaking patients, as well as guests from Arabic countries, China, and India. However, with regard to 'cultural barriers' and the does and don'ts of catering to patients from diverse linguistic and cultural backgrounds, not every aspect can be planned let alone any language commodified. In particular 

tute a large and highly lucrative customer base for MMR. These patients from Saudi Arabia, Qatar or the UAE frequently visit the resort not as individual patients but oftentimes bring along extended family and as such constituted a challenge for the resort's patient managers and hospitality workers. Initially, MMR and its medical clinic assumed that Arabic-speaking patients would appreciate the same level of linguistic accommodation that Russian-speaking guest take for granted, prompting the resort to initiate language courses in Arabic for some of its key workforce and furthermore contemplated to employ Arabic-speaking specialists who, similar to MMR's Russian-speaking medical workers could have been able to provide services to Arabic guests. In fact, as the head of human resources development MT highlighted, similar to MMR's engagement on Russianspeaking markets, employing this particular linguistic resource and commodifying Arabic in marketing discourses could have meant an added value for the resort's medical services and - if compared to similar resorts and clinics - would have marked MMR's medical services as truly distinct for Arabic-speaking guests (personal conversation, 20.11.2014). Continuing our conversation earlier where MT claims that indeed Russian speakers mean an added value for the services the resort, speaking Arabic clearly does not:

but NOT with Arabic. they don't like it when we speak Arabic. we had Arabic, we had Arabic-speakers. they often come in groups with translators so they can make sure that no one overhears them. initially we thought that we have to train people in Arabic as we did with Russian, but we learned that it does not make any sense. it is not desired by guests (personal conversation, 20.11.2014)

This effective devaluation of linguistic resources is striking as it shows the uncertainties in planning the best policies to linguistically accommodate patients from different healthcare markets as much as it highlights what is at stake for whom in case efforts to commodify particular languages and speakers fail. In fact, while this led MMR to conclude that not every patient visit can be planned by assigning appropriate speakers to patients with certain linguistic backgrounds, this apparent volatility also shows who loses out in efforts of language commodification, an instance that was pointed out by the marketing and public relations specialist we already met earlier on a tour through the resort. On the one hand he accentuated that Arabic classes were largely conducted in vain, taking up the time of medical- and hospitality workers and MMR's resources; on the other hand it manifested cultural stereotypes and led to an effective devaluation of the language skills of the resort's Arab-speaking workforce (personal conversation, 13.09.2014). For MMR, the reasons explaining the impossibility to commodify Arabic remain speculative and both JL and MT attribute it to the most likely background Arabic speakers in Switzerland have, being first or second generation migrants from countries of the Maghreb who especially in medical contexts do not evoke the same levels of trust English-speaking Swiss workers would. At the same time it also turned out that large parties from countries such as Saudi Arabia or the UAE rather brought along their own translators proficient in both English and Arabic to perform language work with MMR's medical staff or enlisted accompanying family members proficient enough in English to help when medical interpreting became necessary. 
In line with MMR's efforts to attract affluent patients and corresponding to the promotional discourses of Swiss Health, a large share of medical tourists to LH arrive from countries of the former Soviet Union. From the perspective of available linguistic resources, LH's International Office seems well-prepared for many global healthcare markets and employs a multilingual team of patient service managers who act as reference points for healthcare brokers and international patients alike. They examine medical files and documentation from potential patients (also in languages other than German), communicate with prospective patients, provide cost-estimates, help in arranging transport to Switzerland and hotel-accommodation for accompanying family members and consult physicians in the hospital to plan therapeutic treatment and medical procedures. Contrary to some of the medical specialists and hospitality workers at MMR, patient service managers at LH do not guide patients through all appointments in the hospital, but instead meet them on their first day during admission. While they regularly visit patients during their stay and inquire about their needs and wishes, freelance interpreters are recruited on an hourly basis for the patient, but also for family members to assist them during their stay in Switzerland. The patient service managers in the International Office have been previously employed in various medical professions or have a background in either hospitality management or business administration and while all have a fluent command in German and English, every worker shares proficiency in at least another language that is (or may be) relevant to LH's economic expansion in international healthcare. This includes the International Office's head, GV, who is proficient in Mandarin Chinese as well as patient managers speaking French, Italian, Russian or Ukrainian. Among those, it is again Russian that takes a central role and based on admission procedures outlined on LH's website for international (private) patients, all communication with LH may take place in Russian via its International Office. This includes telephone and email-conversations with prospective patients, the translation of medical documents, communication with the patient and family members, but also relates to promotional activities on Russian-speaking markets where communication with stakeholders or local physicians may require a profound knowledge of the language.

Here, linguistic resources play a key role in the work scopes of patient managers, at LH's International Office highlighted by the hiring of initially two Russian-speakers from Ukraine, but who had studied and worked in Western Europe already for some years and who were - apart from Russian and Ukrainian - proficient in both German and English (GV, personal communication, 01.04.2014). Currently, one of them continues to work at the International Office and during the high time of medical travel from countries of the former Soviet Union that lasted from 2010 to early 2014, her Russian skills saw LH well prepared for this particular market. However, in spite of MMR's approach to specifically enlist Russian speakers with 'post-Soviet' cultural backgrounds, at some point in 2014 the management at LH's International Office seemed to notice shifting preferences among its Russian-speaking patients that would effectively devalue Russian as a linguistic resource. Whereas language work in Russian still seems indispensable for LH in order to acquire patients, the 

Office while at the same time fails to evoke adequate levels of trust among Russian-speaking patients. In a conversation in between patient assignments, GV as the head of the International Office elaborates on his own assumptions. ${ }^{4}$

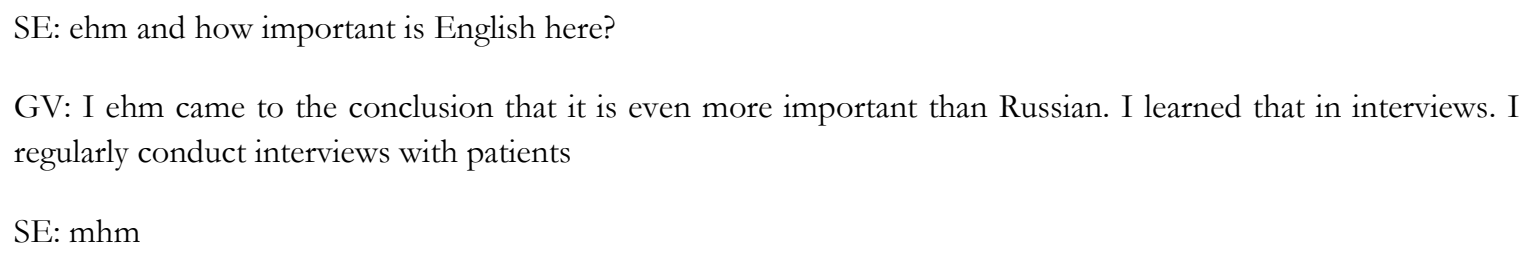
ference. this is maybe my subjective opinion and Mrs. [B.] may have a different opinion. the Russian patient has an entirely different sense of security dealing with someone from the West also because he knows he is outside of the Russian diaspora. this builds trust. you never know if the Russian here knows another Russian

SE: $\mathrm{mhm}$

GV: they value everything non-Russian. I have also noticed that they are much more demanding towards our Russian staff if compared to me as non-Russian. be it because of my name my language

SE: $\mathrm{mhm}$ yes

GV: I noticed this a couple of times. Mrs. [B.] or another patient manager who was also Ukrainian had conflicts. once I was in charge everything went smooth. I don't believe this is because I' $\mathrm{m}$ a man but because I have another cultural background and patients have more respect. I don't know

SE: I also advised Mrs. [B.] that once we get a request for treatment in Russian she must sense whether the patient can also correspond in English. currently she is the only Russian-speaker here and once she was on leave and we could not do anything (personal conversation, 06.05.2014).

Here, a number of aspects are central to better understand the fluctuating value of linguistic resources at LH's International Office. At first, this provides insights into the preferences of Russian-speaking patients to LH, some of whom now seem to be able and willing to converse in English, also enabling them to directly address most physicians and medical staff at the hospital. Here, English also provides a level of anonymity and in fact, GV points out that some of LH's medical tourists are well-known figures from Russian public life and as such not willing to be recognized by Russian speakers working in the hospital. In turn, this also includes GV's own speculations how speaking and at the same time being Russian may lead to more demanding patients who may take up the time of patient managers, contradicting MMR's assumption on the advantages of a '(post-) Soviet socialization' of its Russian-speaking workforce in dealing with Russian speakers. Secondly, as GV indicates, his Russian-speaking patient manager B holds an entirely different opinion about the role of Russian and her role in speaking it to patients, highlighting the uncertainties and highly speculative dimension that attempts to commodify certain linguistic resources entail. Indeed, in a number of conversations in 2014 and 2015, B

\footnotetext{
4 in the interview, [B] denotes the Russian speaker from Ukraine employed at the time of research
} 

the presence of a Russian speaker at the International Office. Thirdly, this also exemplifies how the commodification of a particular language (in this case Russian) also has an impact on language management within the institution itself. Especially the problems in answering requests in Russian via the International Office's Russian-language website show a dichotomy between the provision of extensive services in a certain language for market expansion on the one hand and constraints to effectively live up to that promise through the constant presence of Russian speakers on the other. While for B, speaking Russian initially meant an added value in her professional trajectory, to a certain extent this particular linguistic resource now seems to be less central in the hospital's marketing efforts. In the healthcare industry the answer to these uncertainties may lie in a further flexibilization of LH's workforce dedicated to international patients (Connell 2015) and an increasing use of freelance interpreters who can be hired on an hourly basis. However, similar to MMR this also has broader implications on the processes of language valuation and devaluation, helping us to understand the commodity value of languages among Swiss healthcare providers and how those connect to market conditions, cultural predispositions and attempts to determine the value of the intangible (Heller and Duchêne 2016).

\section{Discussion and outlook}

In this paper I made the attempt to examine the management of multilingual resources for commodification and the negotiation of the fluctuating and unstable value of linguistic resources in the care for medical tourists. Primarily based on Russian as a potentially commodifiable language I highlighted how medical tourism emerges as a site emblematic of the global new economy in Switzerland. At the same time I showed, which particular institutional policies, economic contexts and market conditions have an impact on the ways linguistic resources are managed to become commodities as well as on the limitations in determining an explicit exchange value of a workforce proficient in a particular language. Broadly, this research shows that language commodification to add value to a service or product depends on how institutions relate language to what they offer on the global marketplace for whom and by whom. More precisely and within the scope of this paper, this implies that market expansion through multilingualization and the commodification of languages and speakers to a large extent is dependent upon particular institutions and how they view the commodity value of certain languages and speakers within frequently changing market conditions. In that respect, language commodification cannot be viewed separately from the management of languages and speakers and policing them can be regarded an as integral element of the process which became apparent in both MMR and LH. Here, this also points towards the notion of linguistic resources that can be commodified and that as such are not necessarily intertwined with the general abilities of workers within the new economy but in itself can be of exceptional value to the institution. As we have seen at both hospitals, Russian (or any other language that at a certain moment in time was regarded as potentially useful for market expansion) initially was that valuable linguistic resource at $\mathrm{LH}$ and remains one at MMR. 

and the effect it has on institutional language policies. This became apparent at LH where conflicting views on the commodity value of Russian exist, ranging from being a useful tool for communication to a language (and cultural background of speakers) that apparently evokes distrust among patients. Apart from two competing aspects where service in Russian in marketing and communication with potential patients is indispensable, yet where speaking Russian to guests may not be desired, we have to consider that decision-makers are not always rational and as such call for more fine-grained ethnographic research on language ideologies and cultural stereotypes among decision-makers and marketing experts within institutions (O’Neill 2011). This relates to the desired properties of speakers who commodify their linguistic resources, an aspect that seems to be constant state of renegotiation and change. Here, MMR clearly views proficiency in Russian as an asset that the resort can turn into economic capital on Russian-speaking healthcare markets, yet only those with sufficient experiences of both 'Russian mentality' and way of life are considered fit to adequately represent MMR to those patients. On the other hand, MMR attempted to establish a truly niche product in healthcare by offering services in Arabic that failed because the resort was unable to provide suitable speakers with desired cultural backgrounds. Yet whether successful or not, both incentives came as results of language management and planning efforts by both MMR's medical center and department of human resource development and thus highlight, how language planning within enterprises in the new economy creates the conditions that make the valuation of particular languages possible and at the same time attempt to determine the value of the intangible (Heller and Duchêne 2016). This entails a high degree of flexibility in order to be able to address the unforeseen and to quickly react in case market conditions and patient preferences change. Another dimension became apparent at LH's International Office and while a large share of patients are in fact Russian speakers, speaking Russian while at the same time being Russian (or more broadly, having a post-Soviet cultural background) may not translate into capital gain as such and may in turn even turn out to constitute a challenge to the management of multilingual speakers, putting any competitive advantage of multilingualization into question.

\section{Bibliography}

Appadurai, A. (1986). Introduction: commodities and the politics of value. In A. Appadurai (Ed.), The social life of things (pp. 3-63). Oxford: Oxford University Press.

Bourdieu, P. (1977). The economics of linguistic exchanges. Social Science Information 16(6): 645-668.

Boutet, J. (2008). La vie verbale au travail: Des manufactures aux centres d'appels. Paris: Octares. Cameron, D. (2000). Styling the Worker: Gender and the Commodification of Language in the Globalized Service Economy. Journal of Sociolinguistics 4: 323-347. 
Coupland, N. and Garret, P. (2010). Linguistic landscapes, discursive frames and metacultural performance: the case of Welsh Patagonia. International Journal of the Sociology of Language 205: 7-36.

Chuang, T.C., Liu, J.S.; Lu, L.Y.Y.; Lee, Y. (2014). The main paths of medical tourism: From transplantation to beautification. Tourism Management 45: 49-58.

Connell, J. (2013). Contemporary medical tourism: Conceptualisation, culture and commodification. Tourism Management, 34: 1-13.

Connell, J. (2015). Transnational Health Care: Global Markets and Local Marginalisation in Medical Tourism. In P. Bronwyn, B. Greenhough, T. Brown, I. Dyck (Eds.), Bodies Across Borders: The Global Circulation of Body Parts, Medical Tourists and Professionals (pp. 75-94). Farnham: Ashgate.

Crozier, G.K.D. and Baylis, F. (2010). The ethical physician encounters international medical travel. Journal of Medical Ethics 36: 297-301.

Del Percio, A. (2016). Branding the Nation: Swiss Multilingualism and the Promotional Capitalization on National History under Late Capitalism. Pragmatics and Society 7(1): 82-103.

Dewachi, O.; Skelton, M; Nguyen, V-K.; Fouad, F., Abu Sitta, G.; Maasri, Z.; Giacaman, R. (2014). Changing therapeutic geographies of the Iraqi and Syrian wars. The Lancet 383, 9915: 449-457.

Duchêne, A. (2009). Marketing, Management, and Performance: Multilingualism as Commodity in a Tourism Call Centre. Language Policy $8: 27-50$.

Duchêne, A. (2011). Néolibéralisme, inégalités sociales et plurilinguismes: l'exploitation des ressources langagières et des locuteurs. Langage et Société, 136: 81-106.

Duchêne, A. and Heller, M. (2012). Language policy and the workplace. In Spolsky, B. (Ed.). The Cambridge Handbook of Language Policy (pp. 323-335). Cambridge: Cambridge University Press.

Gal S. (1989). Language and political economy. Annual Review of Anthropology 18: 345-367.

Heller, M. (2003). Globalization, the New Economy, and the Commodification of Language and Identity. Journal of Sociolinguistics 7(4): 473-492.

Heller, M. (2010). The Commodification of Language. Annual Review of Anthropology 39: 101-114.

Heller, M. and Duchêne, A. (2016). Treating language as an economic resource: Discourse, data, debates. In N. Coupland (Ed.), Sociolinguistics: Theoretical Debates (pp. 139-156). Cambridge: Cambridge University Press.

Holborow, M. (2015). Language and Neoliberalism. London: Routledge

Irvine J. (1989). When talk isn't cheap: language and political economy. American Ethnologist 16(2): 248-267.

Kelly-Holmes, H. (2006). Multilingualism and Commercial Language Practices on the Internet. Journal of Sociolinguistics 10: 507-519. 
Marcus, G. (1995). Ethnography in/of the World System: The Emergence of Multi-sited Ethnography. Annual Review of Anthropology 24: 95-117.

McGill, K. (2013). Political Economy and Language: A Review of Some Recent Literature. Journal of Linguistic Anthropology 23(2): E84-E101.

Muth, S. (2015). Russian as a commodity: medical tourism and the healthcare industry in post-Soviet Lithuania. In S. Muth, L. Ryazanova-Clarke (Eds.), The commodification of Russian, Special issue, International Journal of Bilingual Education and Bilingualism. DOI:10.1080/13670050.2015.1115002.

O’Neill, F. (2011). From language classroom to clinical context: The role of language and culture in communication for nurses using English as a second language. A thematic analysis. International Journal of Nursing Studies 48: 1120-1128.

Park, J. (2016). Language as pure potential. Journal of Multilingual and Multicultural Development, 37(5): 453-466

Piller, I. and Cho, J. (2013). Neoliberalism as language policy. Language in Society 42(1): 23-44.

Piller, I. and Takahashi, K. (2013). Language work aboard the low-cost airline. In Duchêne, A., Moyer, M. and Roberts, C. (Eds.), Language, Migration and Social Inequalities: A Critical Sociolinguistic Perspective on Institutions and Work. (pp. 95-117). Clevedon: Multilingual Matters.

Smith, M., Puczkó, L. (2014) (Eds.) Health, Tourism and Hospitality: Spas, Wellness and Medical Travel. London: Routledge.

Swiss Health (2008). Präsentation Medienkonferenz Gesundheitsdestination Schweiz. http://www.sge.com/sites/default/files/Praesentation_Medienkonferenz_Swiss\%20Health_v3_1.pdf

Tan, P.K.W. and Rubdy, R. (2008). (Eds.) Language as Commodity: Global Structures, Local Marketplaces. London: Continuum.

Tissot, L. (2000). Naissance d'une industrie touristique. Les Anglais et la Suisse au XIXe siècle. Lausanne: Éditions Payot.

Turner, L. (2007). 'First World Health Care at Third World Prices': Globalization, Bioethics and Medical Tourism. Biosocieties 2(3): 303-325.

Urciuoli B. (2008). Skills and selves in the new workplace. American Ethnologist 35(2): 211-228.

Urciuoli, B. and LaDousa, C. (2013). Language Management/Labor. Annual Review of Anthropology 42: 175-190.

Viladrich, A., and Baron-Faust, R. (2014). Medical Tourism in Tango Paradise: The Internet Branding of Cosmetic Surgery in Argentina. Annals of Tourism Research 45(3): 116--131. 